\title{
Gesto Musical e Agenciamento Virtual
}

Robert S. Hatten

Em meu livro de 2004 Interpreting Musical Gestures, Topics, and Tropes, apresentei uma categorização do gesto musical baseada em cinco funções: espontânea², temática, dialógica, teórica e tropológica³. Podemos encontrar exemplos de cada uma destas funções gestuais nos compassos de abertura do primeiro movimento da Sonata em Fá Maior op. $10 \mathrm{n}^{\circ} 2$ de Beethoven (exemplo 1).

Exemplo 1: Beethoven, Sonata para piano em Fá Major, Op. 10, no. $2,1^{\circ}$ movimento, tema de abertura

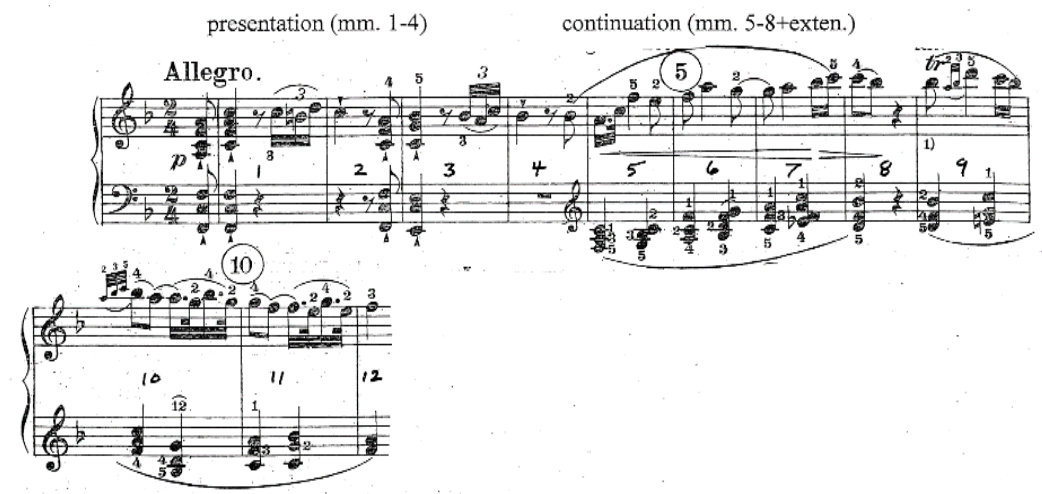

Beethoven inicia com um gesto relativamente espontâneo, injetando uma energia individual em algo de certa forma convencional, gesto de abertura no estilo galante, fazendo uma possível alusão à opera

1 Tradução de Zélia Chueke do texto original enviado pelo autor para fins desta publicação.

2 Palavras e termos em itálico ou em negrito seguem o original. [N.do T.].

3 No original: spontaneous, thematic, dialogical, rhetorical, and tropological. 
buffa. O gesto inicial é definido (apresentado 4 e segmentado) por uma liberação articulada e pela pausa que segue, o que implica igualmente numa "quebra retórica", termo que uso para me referir à ruptura especificada de uma fluência não especificada 5 - neste caso, a interrupção da continuidade sonora. O gesto espontâneo recebe uma resposta dialógica no compasso $2 \mathrm{com}$ a bordadura sobre o dó (onde termina o primeiro gesto) - já implicando um discurso emergente. Após a apresentação inicial, o primeiro gesto é totalmente tematizado quando retorna no compasso 3. Fundamentação e uso são dois critérios de tematização. Quando os compassos 3 e 4 são ouvidos em resposta aos compassos 1 e 2 , um novo nível temático emerge, uma vez que a unidade de dois compassos já então fundamentada é respondida dialogicamente nos compassos 3 e 4 . As quebras retóricas criadas pelas pausas foram então tematizadas pelo uso consistente. Elas com efeito foram absorvidas por uma unidade temática mais ampla - mais como articulações não especificadas do que como interrupções especificadas.

Mas sua perda de força retórica não impõe uma perda do potencial tematizado da quebra retórica e este potencial será preenchido no final no compasso 8 .

Entretanto, um novo gesto aparece no compasso 5 e sua textura contínua é especificada, em oposição à continuidade interrompida agora não especificada6 da primeira unidade de quatro compassos. Embora contrastante, o novo gesto é também relacionado ao primeiro (pela variação em desenvolvimento ${ }^{7}$ da terça ascendente), e por isso pode ser interpretada como um outro tipo de resposta dialógica que mais tarde implica um discurso temático emergente.

$4 \mathrm{Ou}$ ainda «fundamentado » no sentido da apresentação das bases do gesto inicial. Beethoven, Piano Sonata in F Major, Op. 10, no. 2, first movement, opening theme. [N. do A.] No original: foregrounded. [N. doT.].

5 No original: marked disruption of an unmarked flow.

6 No original: unmarked broken continuity.

7 Developing variation. 
A re-contextualização sutil do gesto de abertura (a terça ascendente) é tropológica assim como em desenvolvimento (um exemplo do poder que a variação em desenvolvimento possui para criar um discurso emergente). E o gesto torna-se tropológico graças aos tópicos no compasso 5 que se tornam tropológicos através de : (1) arpejo de fanfarra8, enriquecido pelo ritmo pontuado "nobre" e heróico, (2) estilo cantante, melodia lírica com um rubato expressivo (o deslocamento rítmico regular frequentemente citado como rubato mozartiano) que projeta a linha melódica de cima, (3) um acompanhamento (em acordes) que evoca o estilo de um hino'.

Já no compasso 5, temos evidência estrutural considerável para um discurso gestual temático que explora todas as funções por mim categorizadas. Um certo tipo de agenciamento é sugerido ou implicado por cada uma destas funções: "espontânea" (sugerindo a injeção de energia pelo compositor, adequando um único gesto humano à um contexto estilizado), "temática" (uma entidade construída, sintética ou "individual," com propriedades coerentes e sujeitas a um desenvolvimento reconhecível), "dialógica" (dois indivíduos partilhando um contexto discursivo), "retórica" (interrupção marcada como se fosse pelo lado externo do que seria uma continuidade não marcada, talvez sugerindo um poder agencial externo ou mesmo narrativo), e "tropológica" (uma combinação de propriedades individualizadas numa síntese individual mais alta).

Se considerarmos um caráter afetivo destes gestos, podemos evocar ainda outros aspectos a título de evidência, por exemplo: direção, força dinâmica, densidade e grau de estabilidade métrica e tonal.

Suponhamos que eu escute a terça ascendente do gesto inicial, suave, fundamentada na tônica, caminhando do tempo fraco para o tempo forte, como a proposta de uma tentativa (suave), satisfatória

8 No original: fanfare arpeggiation.

9 No original: hymnlike (chordal). 
(maior, dois acordes de tônica em estado fundamental), e animada (articulações em staccato), medianamente provocativa (a inflexão da terça ascendente, similar à entoação de uma pergunta). De fato, é impossível não escutar o aspecto de fala teatral deste gesto como parte de seu caráter afetivo - e utilizando a metáfora da fala teatral chamando o gesto de "proposta tentativa", estou incorporando a entonação e finalmente a "voz" de um agente humano como parte deste gesto. Mas mesmo se o gesto fosse ouvido como simplesmente "satisfeito," o afeto em si implicaria um agenciamento - que expressa virtualmente uma emoção, ou possui um humor, o de contentamento.

Gostaria de ilustrar aqui de que forma o gesto pode ser entendido como parte de uma teoria mais coesa e compreensiva de agenciamento virtual. Estimulado pelos quatro níveis de agenciamento no discurso dos teóricos proposto por Seth Monahan (2013), sugiro quarto níveis diferentes nas inferências de agenciamento por parte dos ouvintes ( Figura 1), indo de (1) atores virtuais não especificados para (2) agentes humanos virtuais, (3) seus papéis de atuação nas trajetórias dramáticas (ou narrativas) e (4) sua transformação como parte de uma consciência e subjetividade mais amplas que são partilhadas (e negociadas) individualmente por cada ouvinte.

Figura 1: Quatro níveis básicos de inferências de agenciamento virtual dos ouvintes em música.

SUBJECTIVIDADE virtual (quando negociadas com subjetividades individuais dos ouvintes)

ATORES virtuais (preenchendo papéis em trajetórias dramáticas ou narrativas)

AGENTES virtuais (com características humanas)

ATUANTES virtuais (fontes individuais não especificadas de ações) 
Estes quatro níveis guiam a interação coerente de forças musicais, gestos, tópicos e alegorias ${ }^{10}$, incorporação, identidade, e a continuidade do discurso musical, na medida em que eles encaminham à expressão (não à mera representação) e ao desenvolvimento em andamento (não apenas à sucessão) de emoções e pensamentos virtuais, ambos motivados por situações em mundos virtuais, e enriquecidas pela auto-reflexão. Compositores ocidentais de música tonal puramente instrumental desenvolveram estratégias composicionais para colocar em cena diversos níveis de agenciamento virtual, compensando assim a falta de referência, por parte da música, a situações do mundo real.

A Figura 2 apresenta uma série de quatro inferências transformadoras ${ }^{11}$, levando a cada um dos quatro níveis de agenciamento : o ato de virtualizar'2, move atribuições de agenciamento dentro da música propriamente dita, quando energias musicais são compreendidas como ações de um ator virtual não especificado; a incorporação é crucial para interpretar aquele ator como um agente humano virtual (com gestos humanos e emoções); o tornar fictício ${ }^{13}$ nos capacita a entender os agentes virtuais como atores virtuais, que desempenham papéis numa estória que se desdobra dramaticamente num mundo musical virtual; a interiorização ${ }^{14}$ transforma estes papéis virtuais em partes de uma subjetividade mais ampla, como linhas que competem entre si numa consciência singular, com tudo que se engaja em termos de interpretação psicológica ou espiritual. A reconstrução hipotética destes níveis e inferências eleva logicamente uma escala de complexidade, mas o processo cognitivo real implicado e suas ordenações precisas são sem dúvida muito mais complexas.

10 No original: tropes.

11 No original: transformative inferences.

12 No original: virtualizing.

13 No original: fictionalizing.

14 No original: interiorizing. 
Figura 2: quarto inferências transformadoras associadas aos quatro níveis de agenciamento virtual

INCORPORAÇÃO como Agente

TORNAR FICTÍCIO ...... como Ator (em estória, drama ou narrativa virtual) INTERIORIZAÇÃO ........................................ VIRTUALIZAÇÃO como Atuante

A virtualização emerge de outras diversas capacidades de nível inferior - mesmo que dependente delas - por meio das quais percebemos e interpretamos inicialmente as emissões sonoras:

a. percepção gestalt (forma temporal e imagística coerente). Esta é nossa capacidade de perceber uma emissão sônica como possuindo uma forma significativa (a gestalt) ou exibindo modelos claros, e possuindo assim identidade como um evento.

b. generalização trans-moda/5 (como um perfil energético). Nossa capacidade de entender um evento sonoro ou uma sequência como possuindo, ou no mínimo projetando, um gasto de energia com um perfil equivalente em qualquer área senso-motora. Servindo-me da mesma argumentação que apliquei ao falar do gesto, o evento é transmodal.

c. energia geradora (fonte). Nossa capacidade de inferir sobre uma fonte geradora para aquela emissão coerente de energia sonora.

d. foco individualizador (identidade focal). Nossa inferência sobre a possibilidade deste evento possuir suficiente coerência ou particular projeção dinâmica para sugerir uma fonte ativadora singular, que pode ser identificada (ao contrário de uma fonte difusa, como no caso do vento).

e. efeito (como estigma). Nossa inferência sobre o evento como um efeito do uso de energia por alguma fonte individual.

15 No original: cross-modal. 
f. ação (atuante). Nossa inferência sobre o estigma do evento poder ser entendido como uma ação da parte de um atuante (não especificado, mas individual) e portanto reveladora da identidade do atuante.

Se quisermos inferir sobre um evento dinâmico como uma ação, devemos pressupor um atuante - seja o que for que esteja agindo. No caso da música, podemos simplesmente considerar um agente realmente atuante que produz som. Até mesmo se os performers não estiverem visivelmente presentes fisicamente, um som pode ainda ser considerado como tendo sido emanado por uma fonte real, seja diretamente, no caso da voz, ou indiretamente, no caso de um instrumento. Tais atuantes seriam considerados reais.

No entanto, outro tipo de inferência, que é um ponto de partida crítico para minha teoria, é a capacidade de imaginar um agenciamento virtual nos sons propriamente ditos. Sendo assim, uma ação internamente musical implica um atuante virtual. Inferimos aqui que uma ação encontra sua fonte virtualmente na música propriamente dita e não apenas num performer real. Aqui, estilos musicais e estratégias composicionais provêm vários tipos de suporte para tal inferência especial. Descrevi (Hatten, 2004, p.101-2; 109) uma capacidade cognitiva "gestalt temporal" que nos torna capazes de escutar uma série de notas não como as contas de um cordão, mas como um fluxo singular de energia - sendo assim, podemos escutar uma formatação energética virtualizada através do tempo como se fosse o movimento de uma energia sustentada através do espaço. Esta capacidade, que consideramos garantida (corretamente, uma vez que possui raízes evolutivas profundas), é a base para nossa experiência de movimento e gesto em música. Ouvir movimento através do tempo pode parecer uma inferência simples sobre o som. Podemos facilmente ouvir movimento através do espaço como implicador de um emitente real se movendo através do espaço - como os homens primitivos conectavam sons na 
trajetória de um perseguidor que normalmente pareceriam desconectados. Mas quando se trata de música, somos capazes de imaginar os sons propriamente ditos como capazes de implicar sua própria fonte energética e localização espaço-temporal num mundo virtual de timbres. Este é o salto profundamente imaginário da virtualidade, e pode acontecer antes da especificação de qualquer atuante como um agente virtual. Ouvintes estritamente formalistas podem não visualizar desta forma (embora eles possam não estar conscientes do quanto eles de fato visualizam), ao invés disto, clamam gostar de vários gestalts energéticos quando entram numa estrutura hierárquica ou teia de relações - correspondendo aproximadamente ao conceito de Eduard Hanslick (1854) sobre "formas que se movem."

Evidências posteriores fornecem suporte contínuo para o que vem a ser uma simulação progressivamente imaginária. Num nível mais básico, alturas cuja frequência torna-se progressivamente mais ampla, são ouvidas como descendentes. E acentos fortes são tipicamente ouvidos como sendo orientados para baixo. Porque? Porque estas direções do som correspondem mais proximamente, analogicamente, à nossa experiência de peso no mundo físico em que vivemos - estamos sujeitos à força de gravidade que orienta nosso ambiente em termos de "para cima" e "para baixo", como Steve Larson (2012) demonstrou exaustivamente. Assim, construímos prontamente um ambiente virtual (Hatten 2004, 115) no campo do som, que se baseia, ao menos minimamente, nestas dimensões. Música que possui organização tanto tonal como métrica pode posteriormente estabilizar um ambiente musical virtual fornecendo plataformas claras, segundo Larson, em direção às alturas que são atraídas pela gravidade, para mencionar apenas uma de suas forças. A alternância de tempos fortes 16 e tempos fracos 17 resguarda em nossa linguagem teórica o sentimento

16 No original: upbeats.

17 No original: downbeats. 
incorporado do ambiente físico virtual da métrica, constantemente "refrescado" por assim dizer, pela recorrência de cada tempo fraco subsequente.

Acessando um ambiente musical virtual que estes direcionamentos restringem, compositores poderiam começar a sugerir energias agenciais virtuais 18 (Hatten, 2012) através da contradição da força de gravidade virtual, por exemplo. Um salto para cima poderia ser motivado por uma injeção de energia agencial virtual, sustentando desta forma a continuidade de um agente individual virtual, movimentando-se através de um espaço ambiental virtual. Uma série de inferências leva o ouvinte de um atuante virtual a um agente virtual, compreendidos neste caso como sendo dotados de aspectos agenciais humanos:

h. independência (inferida a partir da contraproposta do constrangimento de um ambiente virtual) implica um agente virtual, mas o caráter cada vez mais humano daquele agente virtual vem à tona quando inferimos:

i. intenção (interpretada como uma superação deliberada dos constrangimentos), consequentemente um agente propositadamente atuante, $\mathrm{e}$

j. caráter gestual (qualidades afetivas do aspecto energético de um evento), que implica um agente virtual que sente.

k. identidade agencial frequentemente conquistada através da tematização, cujos meios incluem um projeto inicial e uso, assegurando reconhecimento contínuo. Mas identidade pode de alguma forma ser preservada, e sua

I. persistência ou continuidade (interpretando mudança como crescimento) garante seu desenvolvimento progressivo - um desenvolvimento que pode inicialmente ser entendido como crescimento emocional. Dadas as complexidades do agenciamento humano, fica fácil

18 No original: virtual agential energies. 
dar o salto de inferência 19 subsequente para o crescimento psicológico ou espiritual ou caráter de desenvolvimento no sentido da construção (Bildung).

A interpretação de traços energéticos como agentes independentes não precisa ser continuamente de baixo para cima; uma vez que é dado o salto imaginário para ouvir um agente virtual não o reconstruímos constantemente com todos os eventos. Mais ainda, um agente virtual pode ser inferido mesmo quando uma linha "se rende" 20 a forças musicais como costuma colocar Larson. Conforme demonstrado em 2012 (Hatten, 2012), a ênfase na dinâmica, no ritmo, na aceleração e nos acentos podem enfatizar o movimento de um agente virtual em direção à um objetivo implicado pelas forças musicais. Em todo caso, podemos escutar a independência das energias agenciais e assim uma linha musical ou melodia que possui continuidade temporak1 também sustenda uma continuidade como uma série de ações por uma força única - e desta forma, a continuidade do agente virtual que esta pressupõe.

Mas uma melodia é simplesmente a mais básica das ingerências agenciais. Contraponto também pode motivar o desejo de projetar um agente único, através do que chamo de countraponto refrativo22, no qual os contrasujeitos são derivados do sujeito. De fato, toda textura musical pode adquirir um caráter agencial de integração. Introduzi (Hatten, 2015), melos como um termo apropriado para este fluxo agencial de integração, que é a passagem ou o caminho de nossa atenção focal quando ouvimos música.

Evidências posteriores para um agenciamento virtual humano, em oposição a um agenciamento virtual puramente mecânico ou animal, pode ser encontrado no caráter qualitativo de eventos musicais enquanto

19 No original: inferential leap.

20 No original: "gives in".

21 No original: "temporal continuity".

22 No original: refractive counterpoint. 
gestos completos, que defini como formas importantes, afetivas, energéticas através do tempo (Hatten, 2004). O que torna um gesto imediatamente afetivo e consequentemente humano, é a forma particularmente dinâmica da energia, toda vez que esta for análoga à expressão física de alguma ação ou emoção. Mas assim que ouvimos o gesto como agenciamento virtual humano incorporado, começamos a esperar uma persistência contínua desta identidade agenciak3 e ainda outras estratégias composicionais podem sustentar esta inferência. A continuidade de identidade pode estar associada a um determinado motivo ou gesto temático que evolui através de uma obra por meio da variação em desenvolvimento 24 , segundo a teoria original de Schoenberg (1975 [1947]). Aqui, a inferência envolve uma interpretação de mudança enquanto crescimento. Se a mudança é muito grande para ser absorvida enquanto crescimento, podemos então inferir um segundo agenciamento-com todos os tipos de possibilidades de sua interação com o primeiro. No entanto, a continuidade da experiência virtual pode também ser sustentada por qualquer um dos outros elementos que analisamos enquanto teóricos da música, como progressão harmônica, ou a abertura de novas óticas de projeções de encadeamento harmônico25, segundo o modelo da análise schenkeriana.

A "tendência das tonalidades" 26 emprestando a metáfora produtiva de Schenker (1921), sugere não apenas as forças musicais teorizadas por Larson, mas também aqueles movimentos aparentemente voluntariosos, porque independentes, que as melodias agenciais parecem representar, opondo-se aos constrangimentos virtuais ambientais da tonalidade (Hatten, 2012). Seguindo esta trama ainda mais adiante, podemos interpretar seja um agenciamento voluntarioso que parece escolher frequentemente de forma espontânea caminhos

23 No original: continuous persistence of that agential identity.

24 Developing variation.

25 Voice-leading.

26 Ou mesmo "vontade das tonalidades". No original: "will of tones". 
particularmente anti-ambientais ou agenciamento reativo em casos onde forças aparentemente externas agem sobre um agente virtual de formas que podem frustrar ou impedir sua ação independente.

Neste ponto, podemos encontrar dificuldades em compreender a proliferação de inferências agenciais. Fred Maus $(1988,1989)$ percebeu a indeterminação ${ }^{27}$ do agenciamento em música. Mas cada vez que um analista acrescenta um suporte para a evidência da identificação agencial, suas diferenças podem ser debatidas de forma similar aos debates sobre estrutura musical e expressão - que frequentemente se provam não menos determinantes. $O$ que contribui para uma interpretação agencial irresistível, como acontece com todas as interpretações hermenêuticas, é seu valor para todos os eventos musicais salientes, trazendo igualmente sentido a todos estes eventos, o que é bastante incomum.

Já no começo de algumas obras do período clássico encontramos contrastes extremos, premissas de conflitos dramáticos, em temas ditos dialéticos. Aqui, gestos musicais contrastantes podem sugerir agentes virtuais opostos, colocando em marcha uma interação dialógica que também pode se desenvolver no tempo. Tais desenvolvimentos contínuos, seja de agentes únicos ou múltiplos, servem para criar um discurso agenciak8. E quanto maior o contraste, mais somos levados a interpretá-lo agencialmente em temos de conflito dramático. Isto agiliza a inferência sobre a terça maior, que é fictionalizante, na qual agentes virtuais exercem papéis de atores virtuais numa ficção, como enacted num mundo virtual. As diversas inferências que sustentam um movimento fictício de agentes para atores podem ser apresentadas da forma seguinte:

m. contraste (implica outro agente) sugere um encontro entre dois agentes virtuais;

27 No original: indeterminacy.

28 No original: agencial discourse. 
n. interação (como em alternância ou imitação) sugere um papel dialógico (e posterior auto identificação), e

o. conflito (o contraste dramático) implicando papéis básicos como protagonista e antagonista.

Bem próximos destes papéis temos:

p. identificação de agenciamento interno vs. externo, que nos habilita a escolher a identificação com um protagonista, através da adoção de sua

q. perspectiva, podemos interpretar energias agenciais ou como ações voluntarias ou como reações à agentes externos. De fato, adotamos o ponto de vista do protagonista virtual com o qual nos identificamos.

Todas estas inferências levam à um desdobramento progressivo de caráter dramático de

r. trajetória (ou série dramática de eventos com um produto), entendida como ficção no mundo virtual da música.

Da mesma forma que as ações em mundos virtuais possuem consequências físicas virtuais, nas quais o agente virtual deve vencer forças físicas tais como gravidade; ações dentro de ficções tem consequências dramáticas, gerando outras ações ou reações, e levando à produtos que preparam o terreno para tipos de arquétipos narrativos explorados por Byron Almén (2008), e as gramáticas narrativas exploradas por Márta Grabócz (2009) e Eero Tarasti (1994).

Mas compreender os agentes virtuais humanos como atores dramáticos significa que podemos conceber suas situações fictícias como suficientes para motivar uma experiência contínua de emoções. Em outras palavras, agentes virtuais experimentam emoções em seus mundos fictícios, e assim podemos estabelecer diretamente uma relação entre estas emoções, ao invés de simplesmente ouvir música como "expressão de" tais emoções, como propõe Peter Kivy (1980, p. 12). Agentes virtuais podem ser entendidos como realmente expressando emoções que são motivadas por eventos virtuais em seus mundos 
dramáticos fictícios. E suas emoções estão sujeitas à avaliação ou apreciação de nossa parte, enquanto ouvintes, mas convincentes quando inferimos agentes virtuais que apreciam situações que se passam em seus mundos virtuais e dramas fictícios, em nossas inferências cada vez mais engajadas.

O nível final de inferência em minha teoria, subjetividade, é aquele ponto onde os atores virtuais se tornam parte de uma subjetividade mais ampla, componentes de uma consciência que pode por vezes pertencer à "duas mentes" em caso de conflito. Por meio desta etapa de inferência, a continuidade da música, já concebível como um melos em andamento, empresta suas ações como correntes de pensamento e sentimento, para criar uma subjetividade mais ampla que por sua vez sugere a Persona ${ }^{29}$ que pensa e que sente - uma consciência que pode refletir sobre seus próprios pensamentos e sentimentos.

Os atores virtuais nesta etapa são submetidos à interiorização em diversos sentidos:

s. sublimação (internalização de ideias). Embora atores virtuais possam parecer perder sua identidade enquanto personagens de um drama e serem absorvidos numa única consciência virtual, eles, no entanto mantém seu status dialógico enquanto trens de pensamento e sentimento dentro de uma consciência.

t. allegoria (interpretar significados posteriores ou mais profundos). Entendendo o ambiente virtual da música enquanto interiorizado na mente, e papéis atuantes como parte de uma Persona no sentido mais amplo, o drama virtual pode se desdobrar no psique como um fluxo de consciência, levando à vários resultados possíveis, na medida em que se relacionam com aqueles encontrados em trajetórias dramáticas ao nível atuante. 
u. ironia romântica (auto-repercussão). A auto-repercussão é adquirida através de deslocamentos entre os niveis de discurso, que podem implicar comentários numa consciência discursiva.

Evidência para pensamentos e sentimentos auto-reflexivos podem ser encontrados em estágios musicais de agência narrativa ${ }^{30}$, na qual um narrador virtual parece comentar o discurso. Neste nível de subjetividade, tal narrador pode ser compreendido como pensamentos mais nobre da parte do protagonista, refletindo e sua própria experiência. Pistas locais para tais "deslocamentos no nível do discurso", como os venho chamando há tempos, incluem gestos retóricos que quebram um fluxo não marcado do discurso, fermatas e suas extensões musicais, inserções do acorde recitativo ou outros marcadores de recitativo, e certas inserções parentéticas ${ }^{31}$.

Interiorização pode levar à uma transformação posterior, de

v. espiritualização (interpretação metafisica). Aqui, uma pessoa pode adquirir uma consciência transcendente na qual a identidade do indivíduo é definida posteriormente, ou através da qual pode-se perder o sentido de identidade individual enquanto esta se mistura com um significado mais amplo.

Embora a subjetividade mergulhe os atores numa consciência mais ampla, estes atores precisam perder seus papéis interativos. Uma ação externa exercida sobre o agente interno central pode ainda desempenhar um papel poderoso ao nível do subjetivo, tão emblemático quanto inevitável, por exemplo. Mas a vantagem da subjetividade como uma etapa na ação virtual inferente é que ela engaja o ouvinte completamente numa experiência paralela massiva ${ }^{32}$ que é guiada pela música, mas situada em termos de referência pelo ouvinte/intérprete, misturando-se num fluxo significativo de "pensamento com sentimento". "feelingful thought."

30 No original: narrative agency.

31 No original: parenthetical insertions.

32 No original: massevely parallel experiencing. 
Enquanto intérpretes, como ajudar a construir (seja como ouvintes engajados, performers participantes ou co-compositores) uma ação virtual num determinada obra e ajudar a criar as condições para a competência no agenciamento virtual que trazemos para outros trabalhos? Em primeiro lugar, um intérprete compara constantemente uma experiência de ação virtual com seu/sua própria experiência, em termos de ações e emoções. Este

w. engajamento envolve uma identificação negociada, através da qual as experiências dos próprios intérpretes podem ajudar a fornecer um terreno referencial para um significado expressivo. Por exemplo, um ouvinte pode se identificar com um protagonista, e outorgar aquele agente virtual com maior força emocional comparando sua expressão virtual com situações reais nas quais o ouvinte experimentou emoções similares. Mais ainda, um ouvinte pode escolher graus variados de engajamento com ações virtuais inferidas, partindo de uma quase completa identificação até uma crescente distância física implicada por partilha empática (sentir com), reação solidária (sentir por), e rejeição totalmente insensível. Idealmente, no entanto, o ouvinte irá ao menos traçar completamente e reconhecer a natureza das experiências fictícias de um agente virtual e segui-las através de discursos e trajetórias dramáticas determinadas pelo compositor, mesmo se não se engajar emocionalmente de forma direta. Tal engajamento, por mais subjetivamente pessoal que possa parecer, é frequentemente garantido estéticamente por estilos tonais nos quais a expressão é fortemente embasada - ao menos a partir dos primeiros passos da ópera na música ocidental.

O engajamento também pode levar a

$x$. aperfeiçoamento, ou desenvolvimento pessoal posterior, em um ou dois modos. A música pode sugerir experiências e situações que vão além daquelas que o ouvinte pode trazer para a obra-expandindo assim potencialmente a consciência do ouvinte, fornecendo ainda expansões e escutas posteriores. E o ouvinte pode começar a escutar e 
ir além em sua compreenção enquanto a música o torna capaz de experimentar "além". Jenefer Robinson (1995; Robinson and Hatten, 2012) praticou este tipo de educação emocional, parte de sua teoria sobre expressividade musical, apesar de se apoiar no modelo antigo de persona, como aplicado pela primeira vez em música por Edward T. Cone (1974). Uma vez que filósofos da música da atualidade como Stephen Davies (1997) e Peter Kivy (2009) escreveram com bastante desdém sobre o conceito de persona, acredito que os múltiplos níveis de inferências que descrevi aqui tornam possível para todos nós, esclarecer mais precisamente quais são as inferências que estão em questão em qualquer que seja a discussão e talvez desarmar algumas das críticas à tal noção de persona sem nuance alguma.

Em segundo lugar, podemos compreender aperfeiçoamento no sentido da imaginação do ouvinte que procede ao lado de seu caminho pessoal, enquanto encaminhada, apesar de tudo, pela trajetória da música. Aqui, o ouvinte lidera a interpretação posterior, adaptando os significados implicados da música a suas próprias necessidades através de alegorias e espiritualização posteriores.

Indo além do subjetivo, acreditamos que a música também acolhe

y. partilha, na medida em que os intérpretes se comunicam entre eles e progridem em suas experiências respectivas, seja em rituais participativos ou conversas informais sobre a música ou instruções mais formais. Esta partilha promove intersubjective confirmation (or modification) da interpretação individual, e leva finalmente a :

z. codificação, ou o estabelecimento semiótico de significados estilísticos enquanto significados culturais partilhados, emergindo de estratégias compreendidas intersubjetivamente (gestual, sintática, tópica, e tropológica) ${ }^{33}$. Para os teóricos da música, isto significa interpretações hermenêuticas, estabelecidas intersubjetivamente como

33 No original: gestural, syntactic, topical, and tropological. 
válidas (senão exclusivas) por experts trabalhando em todos os níveis das cadeias de inferências apresentadas aqui. Eventualmente, este acordo intersubjetivo pode levar a um corpo relativamente objetivo de significado estilístico e cultural.

\section{Conclusão}

Talvez uma parte da indeterminação que experimentamos quando tentamos relatar a ação em música seja devida à inadequação de nossa linguagem teórica. Minha apresentação teórica conduz desde as fontes das forças que, como ações, pressupõem atuantes, passando por agentes mais humanamente incorporados, outorgados com capacidades quase físicas e emocionais, até atores que desempenham papéis em trajetórias expressivas, dramáticas e narrativas, e finalmente ao que chamo de subjetividade. Esta última é com efeito uma forma de consciência partilhada (pela subjetividade virtual inferida que integra todos, ou quase todos os eventos, numa obra musical) com a subjetividade de um determinado ouvinte (ou intérprete) que se identifica com ela e no processo, aprofunda a riqueza que equivale a um fluxo de pensamento com sentimento. Nesta etapa, a subjetividade também se apropria de momentos retóricos como lacunas inesperadas de silêncio, que podem possibilitar ou enriquecer reflexão e autoconsciência.

Embora a categoria agencial de subjetividade envolva uma mescla maior de uma subjetividade de um agente de escuta real, ela permanece virtual num sentido muito importante - como parte de uma imaginação ativa do ouvinte, mesmo quanto ela recorre, evoca e posteriormente capacita a integração de agencias virtuais da música com conteúdos específicos da experiência passada e presente imaginada pelo do ouvinte. A subjetividade inclui não apenas ações e emoções individuais, mas suas consequências, seu desenvolvimento e crescimento - levando à 
auto-repercussão que combina todos estes diversos processos com uma consciência de mais alto nível de significado e de valor, contribuindo para um senso mais profundo da Existência34. Assim é que a música não apenas sugere uma construção (Bildung) virtual, mas guia a aplicação desta construção pelo ouvinte a seu próprio crescimento e individualização enquanto pensamento apaixonado e sentimento ativo da Persona.

\section{Referências}

Almén, Byron. 2008. A Theory of Musical Narrative. Bloomington: Indiana University Press.

Cone, Edward T. 1974. The Composer's Voice. Berkeley: University of California Press.

Davies, Stephen. 1997. "Contra the Hypothetical Persona in Music," in Emotion and the Arts, ed. Mette Hjort and Sue Laver. (Oxford: Oxford University Press), 95-109.

Grabócz, Márta. Musique, narrativité, signification. Paris: L’Harmattan, Collection “Arts \& Sciences de l'art," 2009.

Hanslick, Eduard. 1974 [1854]. The Beautiful in Music: A Contribution to the Revisal of Musical Aesthetics. $7^{\text {th }}$ ed. (Vom musikalisch-Schönen, Leipzig, 1885). Trans. Gustav Cohen. New York: Da Capo. (Reprint of London: Novello, 1891).

Hatten, Robert S. 1994. Musical Meaning in Beethoven: Markedness, Correlation, and Interpretation. Bloomington: Indiana University Press, 1994. Paperback reprint, 2004.

. 2004. Interpreting Musical Gestures, Topics, and Tropes:

Mozart, Beethoven, Schubert. Bloomington: Indiana University Press.

. 2009. "Interpreting the 'Tempest' through Topics, Gestures, and Agency," in Beethoven's Tempest Sonata: Contexts of Analysis and Performance [Analysis in Context: Leuven Studies in Musicology], ed.

34 No original: Selfhood. 
Pieter Bergé, Jeroen D’hoe, and William Caplin (Leuven: Peeters, 2009), 163-180.

2010. "Musical Agency as Implied by Gesture and Emotion: Its Consequences for Listeners' Experiencing of Musical Emotion," in Semiotics 2009: Proceedings of the 34th Annual Meeting of the Semiotic Society of America, ed. Karen Haworth and Leonard Sbrocchi (New York: Legas Publishing), 162-69.

. 2012. "Musical Forces and Agential Energies: An Expansion of Steve Larson's Model," Music Theory Online 18.3. URL: http://mtosmt.org/issues/mto.12.18.3/mto.12.18.3.hatten.php

2015. "Melodic Forces and Agential Energies: An Integrative Approach to the Analysis and Expressive Interpretation of Tonal Melodies," in Music, Analysis, Experience. New Perspectives in Musical Semiotics, ed. C. Maeder and M. Reybrouck (Leuven: Leuven University Press), 315-30.

. (forthcoming). A Theory of Virtual Agency for Western Music. (contracted by Indiana University Press).

Kivy Peter. 1980. The Corded Shell: Reflections on Musical Expression. Princeton: Princeton University Press.

. 2009. Antithetical Arts: On the Ancient Quarrel between Literature and Music. New York: Oxford University Press.

Larson, Steve. 2012. Musical Forces: Motion, Metaphor, and Meaning in Music. Bloomington: Indiana University Press.

Maus, Fred. 1988. "Music as Drama,” Music Theory Spectrum 10, 56-73. . 1989. "Agency in Instrumental Music and Song." College Music Symposium 29: 31-43.

Monahan, Seth. 2013. "Action and Agency Revisited," Journal of Music Theory 57/2, 321-71.

Robinson, Jenefer. 2005. Deeper Than Reason: Emotion and its Role in Literature, Music, and Art. Oxford: Clarendon Press.

Robinson, Jenefer, and Robert S. Hatten. 2012. "Emotions in Music," Music Theory Spectrum 34:2, 71-106.

Schenker, Heinrich. 1921. Der Tonwille [Will of Tones], Bd. 1. Vienna: A. Gutmann Verlag. 
Schoenberg, Arnold. 1975 [1947]. "Brahms the Progressive" [1947], in Style and Idea, trans.

Leo Black, ed. Leonard Stein (Berkeley: University of California Press), 398-441.

Tarasti, Eero. 1994. A Theory of Musical Semiotics. Bloomington: Indiana University Press. 